\title{
Autognosis en las Confesiones de San Agustín
}

\author{
HEBER LEAL \\ Universidad de Concepción (Chile) \\ hleal@udec.cl
}

\begin{abstract}
Resumen
El presente artículo tiene como objetivo mostrar que las Confesiones no solamente pueden ser leídas como una autobiografía, como un itinerario espiritual o como una exhortación divina; sino que, además, puede ser entendida como el despliegue de un pensamiento ávido de trascendencia que posibilita la revitalización de la prudencia como saber moral. Aunque san Agustín no explicita una definición de prudencia en el texto, creo, sin embargo, que es posible construir a partir de su pensamiento una noción de sabiduría que sirva para comprender «el drama interno» que padece el hombre.
\end{abstract}

Palabras claves: Confesión, autognosis, meditación, interioridad, prudencia, hombre y Dios.

\section{Autognosis in the Confessions of St. Augustine}

\begin{abstract}
This article aims to show that the Confessions can be read not ones as an autobiography, a spiritual journey or a divine exhortation; because it also can be understood as the deployment of a bungry thought of transcendence that allows the revitalization of prudence as moral knowledge. Although St. Augustine does not explicitly, a definition of prudence in the text, I think, however, it is possible to build a notion of wisdom on his thinking to belp understand man's «internal drama».
\end{abstract}

Keywords: Confession, autognosis, meditation, inner, prudence, man and God.

Magíster en Filosofía Moral. Licenciado en Educación con mención en Filosofía y doctorando en Literatura Latinoamericana, Universidad de Concepción, Chile. CONICYT-PCHA/Doctorado nacional/2013-21130057. Entre sus publicaciones recientes cabe mencionar "Elementos para pensar una Ética social: saber y acción en Aristóteles" (2013), y "Filosofía y pensamiento en Theatrum Philosophicum de Michael Foucault" (2014). 


\section{Introducción}

Resulta difícil, en primer término, brindar una definición de saber moral más apropiada que la presentada por Aristóteles en su Ética nicomaquea, quien distinguía tres tipos de saberes en el marco de la exposición de las virtudes cardinales referidas a cómo debía ser desarrollada la vida del buen ciudadano: el teórico, el productivo y el moral. Estamos al tanto de que el tercero era llamado phrónesis, vale decir, un saber hacer que prescinde, para su funcionamiento, de principios autodemostrables y que permite instalar al hombre como una figura continua en el tiempo-espacio y, además, como figura resistente frente a las posibles inclemencias del hado. De acuerdo a ese marco teórico, la prudencia está encargada de articular la instalación moral de los hombres y, por tanto, determina la reflexión particular que se debe emprender respecto del hacer y del ser en el mundo.

Ahora bien, aunque no negamos la relevancia de estos asertos, sin embargo, notamos que la prudencia no solo puede interpretarse así, esto es, como un saber-hacer, pues se corre el riesgo de leerla de manera reductible cuando se la describe solamente como un saber actuar (pragmatismo) o como un saber universal (racionalismo). Considero que la clave de todo saber moral es su carácter autorreflexivo, pues permite al sujeto comprenderse a sí mismo en relación a su horizonte de posibilidades; creencia que no negaría la base teórica aristotélica de la noción, antes bien, le ofrecería mayor profundización fenomenológica. Así, tal eventualidad (de llenar el vacío que requiere la prudencia como noción filosófica) es posibilitada por san Agustín a través de las Confesiones, pues este texto nos indica el supuesto de que la intimidad del yo se puede convertir en objeto filosófico de primer orden. Veremos que Heidegger (1999) y Jaspers (1968) coinciden en este punto con nuestro examen, ya que al dialogar en sus trabajos con el hiponense, indican dos claves de lectura a este propósito, se trata de la idea de que el mundo es una tentación que fuerza al sujeto a cuestionarse sobre su forma de ser auténtica y que el texto en cuestión representa un esfuerzo especulativo al mostrar la intimidad de un yo que se cuestiona a sí mismo.

Considero, a modo de hipótesis, que las Confesiones resultan indispensables para iniciar una discusión en torno a la problematización de dos interrogantes filosóficas relacionadas a la comprensión de la idea de prudencia (saber moral) y que toman aquí el carácter de objetivos de investigación, a saber, en qué sentido el texto confesional es un aporte para 
justificar un uso metafísico de la noción de autognosis ${ }^{1}$ (autoconocimiento) en virtud de la exposición de la ideas de interioridad, meditación y trascendencia, por un lado, y cómo se conecta esta perspectiva con aquella entendida en sentido aristotélico, por el otro. Esta empresa emplea el método fenomenológico descriptivo y se articula en relación al aporte teórico-metodológico que ofrece, como dije antes, Jaspers y Heidegger, quienes valoran tanto la profundidad inaudita de las Confesiones en cuanto al examen de la autoconciencia, como la analítica existencial que ellas despliegan en relación a la situación hermenéutica del yo consigo mismo.

Esta relación nos permiten una entrada (hermenéutica) distinta a la histórico tradicional y más en sintonía con la que realiza Heidegger (1999) en su lección de 1921, impartida en la Universidad de Friburgo, titulada Agustin y el Neoplatonismo; texto que muestra que las Confesiones fundan un nuevo tratamiento para la noción de interpretación vista en relación a la «experiencia interior» (Heidegger, 1999: 25-26). Ahora bien, ¿por qué creemos que san Agustín es el indicado para establecer esta relación? Porque en él no se da una división entre la fe y la razón, se presenta el alma como un misterio, se le atribuye valor a la meditación y, lo que no es menor, se niega el escepticismo como vía sustentable para poder establecer un proyecto ético.

San Agustín ve al ser humano como un enigma y como un gran milagro (magnum miraculum). Capánaga indica acertadamente que: «a san Agustín le mueve una urgencia y sed de conocimiento del misterio humano» (San Agustín, 1979: 64) y, además que: «el problema del conocimiento en su más profunda hondura es un problema metafísico, y toda gnoseología desemboca a la postre en la ontología» (San Agustín, 1979: 90; Hessen, 1932: 33).

Las Confesiones de san Agustín han suscitado no pocas interpretaciones y consideraciones teórico-críticas relacionadas a su filosofía, su teología y su experiencia personal; posibilidades hermenéuticas que no escatiman esfuerzos en destacar la inusual hondura reflexiva que le es propia

\footnotetext{
1 Autognosis (selbstbesinnung) es un concepto acuñado a fines del siglo XIX y principios del XX por Dilthey (1982: 61) y hace alusión al conocimiento de las condiciones de la conciencia en las cuales se efectúa la elevación del espíritu a su autonomía. La noción hace, también, referencia al examen de la vida anímica que emprende la conciencia en relación a su propio espíritu. Se trata de la «relación de uno consigo mismo» (Reyes Escobar, 2012: 7). Pese a ello, y teniendo en cuenta que Dilthey no expresa directamente si su concepto lo apoya en el pensamiento agustiniano (Heidegger, 1999), considero que, tomando en cuenta que la etimología de la expresión es «autoconocimiento», no hay inconveniente en emplear en este trabajo la noción para sintetizar las ideas que san Agustín deja dispersas al hablar de interioridad, meditación y trascendencia.
} 
y que incluso le ha granjeado el mérito de ser considerada, desde el punto de vista literario, como una sobresaliente obra de $\operatorname{arte}^{2}$. Sea como fuere, estamos en condiciones de afirmar que las Confesiones es un texto clave, no solo visto desde el ángulo de los fines personales que tuvo el autor para su libro, sino en términos de que constituye un muy buen ejemplo de modelo de autorreflexión. El tratamiento del problema se hace siguiendo la siguiente secuencia: primero, se interpretan nociones típicas de la prudencia como juicio moral, acción correcta y razón desde la perspectiva de la experiencia interior, esto para constatar hasta qué punto san Agustín puede aportar, desde un prisma filosófico, a la fundamentación del saber moral; luego, relacionaremos experiencia interior con meditación para indagar la potencia interpretativa que tiene ésta respecto de la cuestión de la certidumbre moral; posteriormente, en el tercer apartado, se señalan los aspectos que implican, en la visión agustiniana, la relación entre el yo y el mundo; $y$, finalmente, se sostiene que el ejercicio de interrogar-se implica una trascendencia en términos de que facilita la búsqueda de la certidumbre existencial.

\section{Interpretación de las nociones de juicio moral, acción correcta y razón desde la perspectiva de la experiencia interior}

En la tradición aristotélica la prudencia era el saber práctico que el ciudadano debía dominar para desenvolverse correctamente, esta virtud estaba asociada a las ideas de juicio moral, acción correcta y uso de la razón; sin embargo, también se tuvo en cuenta que no todos los hom-

2 C. Vega, por ejemplo, en el comentario que realiza al texto confesional de San Agustín, señala que «las Confesiones encierran belleza y encantos literarios», y es uno de los poemas más «grandes y vibrantes» (Vega, 1974: 7.13). Por su parte, Harnack, citado también por Vega (1974: 9), señala que se trata de «un poema de la verdad, cuya unidad jamás es quebrantada». El mismo Vega, también acentúa el hecho de que las Confesiones guardan en su fondo una «concepción agónica de la vida», y que, «en el fondo, pues, las Confesiones no son más que la descripción soberana de aquella lucha interna, de aquella piscomaquia o combate espiritual de que nos habla san Pablo», es un «estudio psicográfico»y una «angustia por la verdad»(Vega, 1974: 16.17.19). Otro comentarista que elogia este texto es Muñoz Vega, quien señala que es la manifestación de un profundo trabajo de «autointuición y aprehensión de sí mismo»y, también, de «sondeamiento metafísico» (Muñoz Vega, 1958: 527.529). Actualmente se considera que las Confesiones representa una destacada obra literaria por dos razones: por la potencia lírica en que fue escrita y por el género, hasta entonces insólito, que la envuelve, la prosa «autobiográfica». Así, podemos sostener con Jaeger (1968) que uno de los rasgos excepcionales de los «grandes filósofos»es, precisamente, su carácter de «fecundos, inagotables e interrogativos». 
bres alcanzan a desarrollar esta virtud porque predomina generalmente el anhelo de satisfacer las pasiones vitales, para evitar este problema se aconsejó que la acción estuviese guiada por la razón y por una buena intención. Esto, a su vez, alertó a los filósofos sobre otros inconvenientes, como por ejemplo, ¿cuál es el mejor modelo de prudencia ante distintas situaciones morales? Como no se podía establecer, por definición, un carácter universal para esta sabiduría, la comprensión que se hizo de ella desembocó en una suerte de pragmatismo de caso, debilitándose con ello la fuerza reflexiva y, por lo tanto, moral de la acción. El concepto prudencia requiere una nueva discusión sobre la fundamentación de su carácter reflexivo, y la perspectiva agustiniana de la interioridad puede participar en ese diálogo.

Para san Agustín, la sabiduría de vida parte de cierto cuestionamiento profundo que debe emprender cada hombre respeto del estado actual de su existencia, desprendiéndose de esto una sabiduría comprensiva (phrónesis) que surge en virtud del auxilio que brinda Dios en la búsqueda de la certeza que requiere la pregunta zante quién estoy? Si a partir de las reflexiones agustinianas intentamos reformular la idea de prudencia en la actualidad, resultan al menos dos tipos de prudencia, por un lado, la prudencia aristotélica (helénica) que se motiva en la creencia de que la «razón práctica» puede guiar la conducta del individuo frente a la adversidad circunstancial y, por otro lado, la prudencia agustiniana, según la cual hay que creer para comprender de modo que sea posible guiar la conducta al amparo de la fe. La diferencia entre Aristóteles y san Agustín, fuera de las distinciones hechas por la tradición filosófica, ocurre en la esfera de las cosmovisiones que los autores aplican a su pensamiento ${ }^{3}$. Sin embargo, identificamos entre ellos una cierta relación bermenéutica cercana, por cuanto sus propuestas éticas tienen en común las siguientes notas: un optimismo por la felicidad humana, un reconocimiento de la existencia del mundo ${ }^{4}$ y una valoración de la cualidad natural del hombre: la racionalidad.

Mientras Aristóteles cree en el eterno retorno, san Agustín lo hace en la historia del mundo como un proceso cuyo movimiento se detiene en un punto definitivo. La diferencia entre cosmovisiones expresa una oposición dialéctica que se puede apreciar bajo la patentización del valor de la prudencia como método de salvación, ello, claro está, en dos planos distintos, uno inmanente y otro trascendente. Ambas vías, vistas como com-

\footnotetext{
3 En este ensayo se hace alusión a Aristóteles con bastante frecuencia debido a que fue él quien instaló por primera vez la discusión sobre la sabiduría práctica o phrónesis.

Punto que los distancia del idealismo o nominalismo gnoseológico, ya que para éste último, por ejemplo, el mundo no es sino una mera apariencia
} 
plemento para una reformulación de la idea de prudencia, o saber moral, pero sobre todo la segunda, por su hondura vivencial, nos permiten abrir un diálogo con el pensamiento ético actual, el cual se esboza en el marco de la cultura plurisecular, del liberalismo económico y del auge de la técnica.

En las Confesiones se entiende por juicio moral, y desde una perspectiva asistemática, no de tipo universal, sino el saber del sí mismo sobre el sí mismo visto como un saber que surge de la pregunta por la cuestión divina y como un saber que corre el riesgo de perder su hondura si se despliega descarnadamente o solo a partir del domicilio de lo que hoy entendemos, no sin cierta incomodidad, bajo la expresión «racionalidad». Pese a ello, se aprecia una fuerte valoración de la razón, pero entendiendo por ésta una capacidad humana donada por Dios para que el hombre ordene sus sentimientos e ideas, aunque no para conocer lo inefable sin el auxilio de la fe, pues como herramienta mental se vincula a una cosmovisión definida por la centralidad ontológica de Dios.

En la visión agustiniana la disposición a «actuar bien» depende de cada hombre por el libre albedrío, pero decisivamente se lleva a cabo en virtud de la buena voluntad de su Creador (que constituye la causa del sujeto que toma la decisión); tal reconocimiento implanta la clave hermenéutica que significa el experimentar a Dios desde un designio cosmológico paradójico que orienta la conciencia humana. Bajo este pretendido, el hombre no puede consumar la propia vida, ni por deseo ni por pensamiento, sin la presencia de Dios. Dios opera sobre y en el fondo del serhumano como fuente ontológica que le dota de poder y bondad moral. En este sentido, la comprensión moral se efectúa partiendo de una cosmovisión peculiar basada en la convergencia dialógica habida entre Dios y el hombre. Así, se configura la dialéctica a partir de la cual emerge la presencia de la persona en toda su particularidad.

Lo anterior se aclara con la idea de experiencia interior, la que guardando distancia con el daimon socrático, refiere a una intimidad del alma desarrollada en la esfera de la meditación. La experiencia íntima del hombre, al ser además patentizada, genera un cambio en la experiencia gnoseológica personal, pues, en cuanto a intelección de mundo, alude al encuentro que provoca una nueva videre de las cosas. Es evidente que el cambio radical que opera dentro del coloquio entre Dios y el hombre rompe la inmanencia racional del sujeto, su límite y confinamiento inteligible, por cambio de otro estado existencial, más bien ontológico, en razón al descubrimiento gnoseológico que le acontece. Tal acontecimiento es la trascendencia de la filiación interna del alma humana y Dios, como vía y continente de verdad. El uso de la palabra trascender se traduce en clave filosófica en aquello que para san Agustín resulta respecto del fenómeno de estado de gracia. Por 
gracia entendemos básicamente la concesión gratuita que Dios ofrece al hombre. Tal concesión es «amor misericordioso y dulce» (Conf., X. 3, 4) ${ }^{5}$. Presumo que desde el descubrimiento de tal dinámica existencial se actualiza un hecho fenomenológico que otorga sentido a la misma existencia del hombre, pero haciéndolo bajo la figura de un acontecimiento subsidiario que parte de la divinidad y que opera en constante desarrollo moral (Serm., 92.3; En. In PS., 130 14; Ep. 188, 22 y Ioan Ev., 25, 16) ${ }^{6}$.

La interioridad es uno de los elementos más originales dentro de la filosofía agustiniana. La génesis de este elemento radical la podemos hallar directamente a partir de lo expuesto por el Doctor de Hipona en el libro $\mathrm{X}$ de sus Confesiones, cuando se acomete la tarea de buscar a Dios dentro de la región del entendimiento y la fe.

La interioridad está relacionada, por oposición, con lo que San Agustín denomina bajo la expresión desesperación (dispersión), vale decir, funciona como experiencia que pugna con el derramarse del sí mismo en el mundo, acontecimiento que deriva finalmente en un olvido de la posición que se ha de ocupar en él; el filósofo africano narra este movimiento de la conciencia a fin de establecer la interrogante acerca de cómo se consigue el contacto con Dios, el cual no implica caer en una práctica ascética o en una que prive de la relación cotidiana con el mundo.

El efecto producido desde la constatación de la indigencia ontológica, da cabida a reflexiones correlativas sobre el don de la gracia en el hombre que instala en él la indeterminación frente a la verdad. Representar la imagen de tal situación como un fenómeno de la conciencia en donde entra en juego la crítica existencial y el problema figurado por la pregunta ¿quién eres tú?, genera que el sí mismo padezca el efecto de sacudida que descubre al hombre en la situación de disponer su voluntad para poder ganarse a sí mismo. Por ello, no se trata simplemente de lograr la evidencia cartesiana de la propia existencia, sino de buscar el «fundamento» o «causa de existencia», y definir así la particularidad del sí mismo ante el mundo. De esta forma, se abre toda una posibilidad de interpretación de la existencia humana en tensión con la totalidad de la creación.

El hiponense fija el problema de no saber quién es el que se confiesa cuando se confiesa, postulando, de pasada, que el saber de si mismo es incompleto y que esa es la problemática que más acucia al momento de desplegar el testimonio confesional. $\mathrm{Al}$ respecto, tomemos en cuenta lo

\footnotetext{
5 Para las referencias a las obras del hiponense realizadas en el cuerpo del artículo utilizamos San Agustín (1963; 1964; 1967; 1968; 1974; 1979).

En estos pasajes se plantea, entre otros asuntos, que el hombre por medio de la humildad puede conocerse a sí mismo, pues produce un movimiento introspectivo basado en el auto examen, sin engaños ni lisonjas de la propia condición.
} 
que sostiene Heidegger (1999: 30): «Agustín reconoce que no sabe todo de sí mismo» y claramente estamos ante un reconocimiento fenomenológico que sirve de pivote para presentar una suerte de iluminismo epistémico. Consiste en hacernos de una vía de interpretación a partir de la fórmula que nos insinúa en el libro $\mathrm{X}$ de las Confesiones: «me he convertido en un problema para mí mismo» (quaestio mibi factus sum). Para Heidegger este pretendido fundamenta el terreno propio de la discusión metafísica y, al mismo tiempo, el ámbito de mayor dificultad filosófica (terra difficultatis). La meditatio agustiniana se presenta, así, como experiencia fáctica, pues existen cosas en el hombre que ni siquiera él conoce, debido a que él «no se sabe», vale decir, no hay un conocimiento seguro respecto de cuáles tentaciones se pueden resistir y cuáles no: el hombre no se sabe, es decir, no sabe la causa de su existencia y esto es lo que hay que reconocer (Conf., X, 5,7). Pese al detalle negativo del conocimiento inmediato, la voluntad se dispone al bien y con ello se despliega la posibilidad de la aprehensión. San Agustín, además, admite que en el interior del hombre existe un espíritu que sabe todo de él (Conf., $X, 5,7)$.

\section{Meditación y experiencia interior}

Para san Agustín, la meditatio es la comprensión de la interioridad y constituye algo inédito en comparación a los aportes filosóficos tradicionales que aluden al pensamiento ${ }^{7}$, sobre todo en lo que toca a sus connotaciones gnoseológico-metafísicas. Significa una manera contemplativa de pensar y de vivir basada en aprehender la realidad para darle sentido desde el propio examen existencial que torna al sujeto en objeto filosófico. Su lugar de origen es la intimidad de la conciencia, la que tiene por función mostrar que la reflexión posee tanto un sino ontológico como religioso, por cuanto el ser con el cual se dialoga es, en el caso agustiniano, nada menos que Dios. San Agustín entiende que no se trata de separar dos planos de experimentación gnoseológicas, ya que es indistinguible el terreno teológico del terreno metafísico; confluencia que no es obstáculo para un análisis fenomenológico respecto de la unidad del alma y su conexión con el objeto máximo de percepción. El alma es un espacio abierto a lo intemporal.

La meditación no está confinada a una mera experiencia mística, ni a una visión solitaria del hombre respecto del ser-divino, sino que al con-

\footnotetext{
$7 \quad \mathrm{Al}$ contrario del típico monólogo intelectual por parte del agente, se trata de un diálogo con Dios mediante la autognosis. De esta forma el pensamiento adquiere real valor según el filósofo africano.
} 
trario, en san Agustín destaca una nota original al plantear la posibilidad gnoseológica de un coloquio con Dios en el marco de un contexto que hoy se conoce como intersubjetividad. Así, se piensa sobre las posibilidades de obtener la felicidad para todas las criaturas humanas y para el devenir del colectivo, pero se hace desde la interfaz que genera la conversatio con Dios y su designio de sabiduría en el alma; coextensivamente, se proyecta la historia misma de la humanidad a partir de ese eje, prueba de ello son sus conexiones con la Filosofía de la Historia representada por algunos de sus célebres textos, como sucede con De Civitate Dei, donde el centro de la cuestión es una suerte de pensamiento utópico cifrado por la presencia totalizante de su objeto de estudio, Dios. La meditación, entonces, es la clave genealógica desde la que se puede comprender el proyecto ético agustiniano.

La interioridad exige un proceso de meditación que funciona en clave hermenéutica como base para emprender la autognosis. Para realizar una interpretación flexible de la noción de interioridad, no podríamos actuar como lo haríamos con un Aristóteles, me refiero en cuanto a vislumbrar las problemáticas éticas dentro de un «sistema» filosófico eminentemente racional, pues, en el caso de san Agustín no hay una sistematización de similar envergadura, ni siquiera hay signos concretos de una formalización voluntaria; en cambio, podemos considerar las Confesiones como un relato autorreferencial en la medida en que se trata de un diario de pensamientos y vivencias personales firmadas por el nombre propio del autor. En el caso que nos aboca no hay un discurso que busque la objetividad, sino un objeto narrativo y poético bajo el cual subyacen ideas filosóficas inéditas sobre el «milagro» humano.

Es útil, a este propósito, tomar en consideración la distinción hecha por Aranguren (1965: 408-409), según la cual hay filosofía, incluso, en las experiencias vitales o prefilosóficas, vale decir, en aquellas que no están estructuradas con el rigor racional-científico. La personalidad moral de san Agustín desenvuelta en su intimidad descubre una alternativa razonable frente a la interrogante: ¿A qué sabiduría debe obedecer el hombre al momento de actuar en vistas del bien? Sin embargo, las experiencias prefilosóficas son discutibles porque no nos muestran la universalidad de sus conclusiones, lo cual facilita el despliegue de un diálogo con ellas.

Jaspers, frente a este tipo de preguntas, avizora que el significado y la originalidad de san Agustín en el terreno filosófico se encuentran cifrados por la tradición filosófica occidental, porque:

Agustín por primera vez mostró sin restricción la lucha de la voluntad consigo misma; la vacilación, la indecisión, la significación de la decisión que apunta a la totalidad de la existencial y es irrevocable. A la luz de su propia 
experiencia mostró al hombre su debilidad. No le importó poner en evidencia lo vil, lo indigno, como que era parte de la condición humana. Y después mostró la incomprensible certidumbre íntima, la firme seguridad del querer irrevocablemente enderezado a su meta (Jaspers, 1968: 150).

Y además añade que:

Aquello desde lo que quiero lo tengo que experimentar espontáneamente; no puedo producir este fondo, la facultad de decisión. Soy capaz de amar, pero cuando no amo soy incapaz de generar en mí amor. Soy yo mismo, pero no puedo fallar. Tengo que confiar en mí mismo, pero no puedo fiarme de mí mismo. Un natural de hombre bien nacido, un conjunto de rasgos de carácter conveniente y otras disposiciones innatas, no constituyen una base segura (Jaspers, 1968: 151).

La imposibilidad que implica fiarse de uno mismo resulta útil para establecer una reflexión crítica sobre la verdad moral, puesto que al estar en conocimiento de que no existe base segura, se constituyen históricamente nuevos principios morales. El apóstol Pablo es central para poder entender la propuesta agustiniana, ya que él anticipa la paradoja del conocimiento precisamente cuando declara su debilidad moral, exclamando «PPor qué hago el mal que no quiero cuando quiero hacer el bien!» (Rm 7,15-20). Bajo esta expresión emana la inicial incertidumbre moral agustiniana ${ }^{8}$; así, el gran problema moral no se halla en las cosas del mundo, sino en el drama interior del hombre.

De acuerdo al apartado anterior, el itinerario interior es un presupuesto que parte siendo un descubrimiento de la intimidad moral de los sujetos que se quieren revelar como objetos filosóficos. En este sentido, el hombre interior emerge continuamente desde la intimidad conciente mostrando su más profunda indigencia, a lo que se le denomina experiencia interior: factum interioris. Esto se explica por el hecho de que fenomenológicamente se patentiza el principio de bumildad unido a la fuerza de decisión, activando, así, una forma válida de habitar el orbe desde una dialéctica alma-mundo respecto de la que resulta la apertura existencial a lo Otro. Junto a ello, se aprecia una doble figura de la indigencia humana, la primera la podemos traducir en la imagen de la indigencia natural y la segunda bajo la forma de indigencia vivencial. Mientras la primera hace

8 No por tratar los límites del conocimiento humano podría considerarse que san Agustín es escéptico, al contrario, luchó contra la escuela Académica por considerar y defender la certeza de la verdad; ésta entendida como una esencia infinita a la que se tiene acceso a partir de la gracia divina. Así, frente al escepticismo impone la creencia y la comprensión como caminos espirituales para apropiarse de la verdad. 
alusión a aquello designado como carencia de base metafísica de la realidad entendiendo que la «indigencia» está ligada a la deficiencia gnoseológica-, la segunda apunta a la decadencia del contenido de algunas experiencias fácticas acontecidas en la vida humana. Esto último se manifiesta según san Agustín en carne propia: «¿qué acaso me alejo de algo? Dice el Verbo de Dios. Fija allí tu mansión, pone allí depósito cuanto allí te pertenece, alma mía, fatigada todavía de engaños» (Conf., IV, 16).

Cuando San Agustín habla sobre la «fatiga de engaños» comprende por ello el conjunto de experiencias cuyo contenido vivencial ha hecho que su alma se sienta perdida y arrobada a raíz de la negatividad que genera la atención hacia el afuera de la conciencia en detrimento de que se perciba a sí misma como objeto reflexivo. La fatiga se expresa, por tanto, como una evaluación del alma desde el presente que la descubre inquieta; inquietud que parte de la vorágine que supone «existin». San Agustín se refiere así a la experiencia disoluta y libertina que vivió en el pasado, la cual se aclara desde la emergencia de la personalidad moral para romper con la superficie de las apariencias a través de una meditación interrogativa de la propia identidad. Jaspers describe el contenido de la meditación de este modo: «Dependemos de un todo de factores extrínsecos. Nos hallamos en la situación de tener que optar (entre tal cosa y tal otra, entre hacer y dejar de hacer) y de asumir, en consecuencia, la responsabilidad por la decisión que tomamos» (Jaspers, 1968: 151). Se extrae de ahí un segundo corolario: que la «confesión» es una narración de la falta y/o toma de posesión de la impostergable responsabilidad de existir.

\section{Disposición, experiencia y mundo}

El hiponense señala, asimismo, la idea de abandono del mundo, asociándola a una conversión que se traduce en acceso a una experiencia axiológica transmundana y de carácter ético ${ }^{9}$; conversión que se configura desde la relación hombre-Dios, que a su vez plasma un distintivo eje de conciencia. Escribe Jaspers (1968: 151):

Por dos modos de opción ilustra Agustín la certidumbre brindada por la conversión. Cuando se me presenta una pluralidad de posibilidades para mi examen y opción, querer y poder no son una y la misma cosa; opto por algo particular e individual y lo realizo en la medida de mi alcance. En cambio, cuando la opción atañe a mí ser mismo en su totalidad, querer y poder

Experiencia ética pues se trata de un vuelco moral que compromete pensamiento y acción, un cambio de cosmovisión. 
son una y la misma cosa: mas este querer me viene de un modo incomprensible. No puedo quererlo como mi querer, sino que por obra de él quiero (Dios). No soy espectador de mi decisión. No dispongo su realización. Al decirme estoy ya decidido. En esta decisión no soy dueño de mí. Depende de que Dios me brinde a mí mismo.

La conversión mediada por Dios, devela al homo interior a nivel de experiencia fáctica, brindando la voluntad para acceder al mundo con un temple distinto al natural; sin embargo, cuando acontece tal donación o reconciliación moral, en el estado de acceso, Dios resulta inexplicable debido a que su conocimiento no deriva de esfuerzo necesariamente humano. De acuerdo a la apertura de la experiencia ontológica que reviste el acontecimiento confesional, resulta pertinente restituir la importancia del logos como palabra y como disposición gnoseológica, pues, al desplegarse, moldea la voluntad del hombre vía autocomprensión. En este proceso, san Agustín atribuye importancia ontológica a la palabra, puesto que al exhibir al objeto de reflexión, con sus efectos de internalización, se logra un cambio de comportamiento radical que termina por constituir al ente confesional en problema filosófico constante. Ésta constante está en la línea de proposiciones éticas contemporáneas como las que plantea Zambrano (1987: 21): «toda palabra requiera un alejamiento de la realidad a la que se refiere; toda palabra es también, una liberación de quién la dice». San Agustín propone lo siguiente a este propósito:

Mis Confesiones..., leídas u oídas, excitan el corazón para que no se duerman en la desesperación y digan: No puedo; y le despierte al amor de Tu misericordia y a la dulzura de Tu gracia, por la que es fuerte el flaco que llega a tener por ella conciencia de su flaqueza (Conf., X, 3, 4).

San Agustín da cuenta de la eventual instalación de una personalidad moral continua a través del tiempo desde la constatación de la debilidad que supone la pregunta ¿quién soy?, y, por tanto, despliega toda una axiología descriptiva de la vida interior. Sin duda el propio caso de san Agustín representa el asunto en carne propia ${ }^{10}$, al apuntar que el filosofar parte de un sentimiento y de una crítica de la relación unidad-multlipicidad. De ahí se desprende la hipótesis de que la vida es un cómo del ser: un acceder, una ejecución y una experimentación, pero se trata de un experimentar lo que está frente a los ojos: un experimentar tentaciones. En ello radica precisamente la inquietud del hiponense, específicamente, en el hecho de resaltar que una tentación pone en obra la posibilidad de perderse o ganar-

10 Según Chávez (2010), se trata de tener esperanzas frente al probabilismo ético propuesto por los escépticos (Académicos) de su tiempo. 
se a sí mismo; juego que expresa cierta intencionalidad de la conciencia, pero que, en esencia, remite al direccionar del sujeto prudente. Así se enuncia la gran preocupación de san Agustín en torno al problema que aparece en su propia persona, siendo el factum que hace las veces de desafiar la estabilidad de la personalidad moral, en términos estrictos, del ethos. El actuar, el hacer, el modo, la vigencia y el cómo del ser, son formas en que se constituye una facticidad del ejecutarse del ser que no emerge de manera accidental en razón a que la vida implica, como experiencia de las tentaciones, y como se ha estado insistiendo, la actitud reflexiva constituida como anticipación del orden moral. Ello instala, como trasfondo, la capacidad de comprender y develar el valor hermenéutico de las acciones morales.

La idea de tentación también reviste especial interés dentro de esta interpretación, porque, siguiendo al hiponense, el mundo nos habla, nos absorbe, encanta, y es, como diría Baudrillard (2011), pura «seducción», pero no orientada al mero provecho del yo, sino a que surja un aprendizaje de la experiencia y, por efecto, se ponga al descubierto lo que está escondido en el hombre, ergo, pueda éste tenerse a sí mismo y presentarse como un ser accesible a la experiencia vivencial.

De esta forma, la vida humana se comprende como una búsqueda y aprendizaje que debe ejecutar el propio hombre mediante una ardua problematización del sí mismo. El poner al descubierto refiere a la genuina textura que fuerza las acciones: esse - nosse - amare (ser, conocer y amar). Son dimensiones de la existencia que constituyen, de suyo, cierta tenacidad que posibilita el aparecer de las tentaciones y la actitud comprensiva de su interpretación. La pasión, el anhelo y la obsesión que pueden ocasionarse en todo este juego de comprensión hermenéutica del yo, constituyen cualidades heroicas que hay que vigilar moralmente, pues no son per se elementos prudenciales. Basta recordar que detrás de la hebra que nos permite el análisis de esta virtud, se halla, pero como símbolo de presentación fenomenológica, la bumildad. La clave hermenéutica para hacernos de una inteligencia moral consiste, entonces, en saber que: quaestio mibi factus sum.

El tomarse a-uno mismo como importante implica pensar en la figuración de la vía inversa, esto es, perderse a sí mismo en la dispersión de las cosas. El hombre, al anteponerse, antepone su mundo, concibiendo el sentimiento correlativo de tomarse a sí mismo como decisivamente elemental, figura moral de la soberbia. Empero, esta inmanencia del mundo en el actuar del hombre conlleva a una pérdida del propio ser en su tenerse genuino; el hombre se halla entre-tenido en el mundo y en la profundidad impuesta por el yo. Para san Agustín, esta hexis que provoca la tentatio 
constituye la afirmación de la caída abismática del alma ante la verdad. Y el darse por enterado de esto, en sentido vivencial, genera que el hombre se vea desde fuera, como un logos que trasciende el yo y el mundo. La ecuación logos filosófico más logos religioso -que es la meditación metafísica de la propia existencia en referencia a las cosas o a Dios- provoca la justificación de la prudencia como trascendencia del sujeto que la encarna. El logos religioso -o también: referibilidad radical - le da sentido metafísico al concepto, abriéndose a esta referibilidad desde cuyo horizonte se descubre a sí misma como unidad ontológica diferente al mundo y, por tanto, cercana a Dios.

\section{Trascender es interrogar-se}

Con san Agustín advertimos que la disposición racional práctica tiene como principal objeto de examen tanto la interioridad de la conciencia humana como sus paradojas, las que están en relación a la dimensión exterior y referencial del alma, puesto que la acción que deriva de la meditación resulta de la decisión como justificación de sus efectos morales. Mas, el autor lo expresa en el libro X de las Confesiones y, con ello, señala el máximo presupuesto de autocrítica antropológica del sí mismo en el Pensamiento Antiguo. «Existen cosas en el hombre que ni el propio espíritu del hombre conoce... A qué tentaciones puedo resistir y a cuáles no» (Conf., X. 5, 7). En este punto queda de manifiesto la connotación religiosa que el autor de las Confesiones le atribuye al misterio del autoconocimiento.

San Agustín, simultáneamente, reflexiona sobre la diferencia entre lo que entiende por animalidad y humanidad, señalando sobre el primero que los individuos a los que alude: «No han recibido el don de ver la verdad del conocimiento, debido a que no tienen la capacidad de interrogar» (Conf., X. 6, 10). Mientras que llama a la potencia o don apropiativo del hombre: razón que juaga (iudex ratio) (Conf., X, 6, 10-11); junto a ello, añade que aunque los animales no tengan esta iudex ratio, no obstante, comparten con nosotros otros rasgos, más elementales como la vida, la fuerza y la potencia: algo que previamente los griegos llamaron energeia.

La trascendencia es la ejecución fáctica dirigida hacia la verdad del conocimiento; claridad existencial que presupone, como movimiento óntico-ontológico, la existencia previa de la capacidad de interrogar. Esto es relevante por cuanto la problemática del interrogar acerca del fundamento de la conciencia se inaugura genéricamente con san Agustín; acontecimiento filosófico que posteriormente será reconocido por el autor de Ser y tiempo (Heidegger, 1999). 
La categoría trascendencia se expresa en dos planos distintos, el teológico y el metafísico. El primero incumbe a la especie humana y se define en relación a la culpa original adánica (tomando como referencia la promesa divina de salvación acogida por el seguimiento firme de los preceptos divinos, la que se materializa en la figura clave y redentora de Cristo); el segundo, en cambio, es de carácter particular y se desarrolla en el orden de los actos morales aludiendo a la existencia concreta que se resuelve tras el consorcio de la voluntad y de la razón. En ambos casos se efectúan experiencias religiosas, no obstante, la primera se debe tomar como de carácter doctrinario. Capánaga señala que el hombre se constituye bajo una triple definición: a) imagen de Dios, b) ser caído en la culpa, y c) homo rationalis, o animal movido por un verbo interior «en que se cifra toda su alteza y dignidad» (San Agustín, 1979: 64). Ésta última definición alude necesariamente al dogma y a la restricción de la decisión humana y posee, así, un sello marcadamente histórico-cultural que le preexiste, ya que constituye la ejecución de un relato fundacional orientado al desarrollo de un futuro indeterminado. La segunda forma de interpretación de la categoría trascendencia, en san Agustín, es más dinámica y se establece como objeto de reflexión filosófica, ya que alude a la praxis, vale decir, a la interioridad y a la comprensión de los momentos actuales-contingentes de la existencia humana. En este caso, el hecho de trascender es tributario del hecho de interrogar, de la misma manera que la intención de comprender el misterio de la propia existencia deriva en la definición de un universo práctico. La autognosis se genera por manos de la iudex ratio pero en complemento con la fe e implica creer antes de comprender; dándose así lugar a la intervención divina. La conjunción creencia-comprensión (Contra acad. III. 30, 43) no se da tanto en el plano de la universalidad veritativa cuanto en la autognosis (Serm., 123 2,4). Esto conecta con la consideración hecha por Conderana (2002), según la cual la prudencia aristotélica aprehende los medios correctos de manera intuitiva.

Por todo esto, podemos declarar que lo peculiar del análisis hecho por el filósofo africano ha consistido en relacionar intelecto y trascendencia como si fuesen dos extremos de una misma línea dinámica de la existencia humana ligada a la energeia, es decir, la trascendencia solo se haría posible en tanto el hombre - por vía de intelecto y de fe- sobrepase la vida propia a fin de alcanzar a Dios (Conf., X. 8, 12). El sobrepasarse en el fondo consiste en desasirse del velo del yo, velo del ego que se presenta, no solo en la atractiva pujanza material de las cosas sobre los sentidos, sino en el rechazo del llamado amoroso de Dios. Este movimiento del alma favorece la claridad en que debe trabajar la intuición de los criterios morales. 


\section{Conclusión}

El doctor de Hipona sostiene, como se ha dicho en lo precedente, que el alma humana es el mayor de los problemas filosóficos. La lucha interna no implica una confusión mental, sino una condición de la existencia a la que se vincula la tentación como categoría existencial de relación del sí mismo con su propio fundamento. El trascender implica sobrepasar la vida particular (estado normal del alma) y da lugar a la solución más apropiada para el problema de la lucha interior: resolver la paradoja gnoseológica del ser humano, parcialmente, y en la medida en que el proceso no se detenga por la dispersión. El misterio está relacionado con la memoria y - cuando se da tal conjunción entre memoria y misteriosurge de ella la posibilidad de la autognosis como ejercicio hermenéutico, lo cual implica creer que el alma no se pueda captar a sí misma suficientemente.

En lo que concierne a la dimensión moral, la respuesta que se deduce a partir de la interrogante de si es o no posible comprobar que el conocimiento de si mismo, es importante para tratar la noción prudencia, resulta afirmativa, porque, en primer lugar, el ganarse (o el perderse) a sí mismo constituye un paso importante en la constitución de un éthos y, en segundo lugar, si existiera algún proyecto ético que considere fundamental aclarar el contenido de la prudencia o saber moral, no le será posible prescindir para ello de un ejercicio autoreflexivo; ejercicio que refiere a la capacidad que tiene el agente moral de descubrirse, de comprender su dimensión afectiva, de establecer su principio de acción y de encontrar sus debilidades gnoseológicas. En este sentido, la autognosis es un ejercicio de cuestionamiento existencial necesario para orientar la prudencia, porque supone una actitud crítica y humilde del yo. En efecto, la autognosis no solo se relaciona con el pensar y con el conocer, sino que con el actuar, pues, en el fondo, supone una aclaración de los presupuestos morales en virtud de la descripción de los rasgos característicos de la vida particular. Esta aclaración es requerida por la prudencia para llevar a cabo la deliberación de la acción, ya que la prudencia, al no ser un saber universal, requiere de una hermenéutica afectiva. Por ello, establecer un proyecto ético requiere más que de un método, de un camino espiritual, el cual debe integrar, antes que la voluntad y la razón, la comprensión y la creencia; ya que tales elementos corresponden a la hermenéutica del drama interior que conforma la acción moral. Con ello, he querido mostrar que la prudencia o saber moral debe ser tratado más como una comprensión hermenéutica de la acción (autognosis) que como una racionalidad calculada y pragmática. 
La secuencia de lo desarrollado hasta ahora deja entrever que al hablar de autognosis estamos ante un concepto construido en base a un hilo conductor brindado por algunas ideas filosóficas diseminadas en las Confesiones, hilo conductor que también ha sido respaldado por Heidegger. Ahora bien, esta construcción ha sido llevada a cabo con el propósito de aportar elementos nuevos a la cuestión del fundamento y del contenido del saber moral. En efecto, he mostrado un conjunto de elementos que acentúan la atención en la idea de autoreflexión como requisito para pensar en una sabiduría moral; sin embargo, no creo que la autognosis deba sustituir por completo la noción de prudencia, sino que funciona como recurso metodológico en la medida en que resalta la necesidad de un viraje de fundamento en base a una hermenéutica de la acción.

\section{REFERENCIAS}

-Aranguren, L. (1965). Obras. Madrid. Editorial Plenitud.

-Aristóteles (1985). Ética Nicomáquea (J. Pallí Bonet, Trad.). Madrid: Editorial Gredos.

-Baudrillard, J. (2011). De la seducción. Madrid: Ediciones Cátedra.

-Conderana, J. (2002). El conocimiento de los principios prácticos en Aristóteles. Salamanca: Publicaciones Universidad Pontificia de Salamanca.

-Chávez, P. (2010). San Agustín. Apuntes para un diálogo con la ética actual. Santiago de Chile: Editorial Universitaria.

-Dilthey, W. (1982). Gesammelte Schriften (19 vols.). Stuttgart-Göttingen: Ediciones de BG. Teubner - Vanhoeck und Ruprecht.

-Heidegger, M. (1999). Estudios sobre mística medieval. México: Fondo de Cultura Económica.

-Hessen, J. (1932). Agustins metaphysik der erkenntnis. Münster: Augustinus Magister.

-Jaeger, W. (1968). Paideia: Los ideales de la cultura griega. México: Fondo de Cultura Económica.

-Jaspers, K. (1968). Los Grandes Filósofos II. Los fundadores del filosofar: PlatónAgustin-Kant. (P. Simón, Trad.). Buenos Aires: Editorial Sur. S.A.

-Muñoz Vega, P. (1958). La existencia, su alternativa y su misterio en la síntesis de San Agustín. Gregorianum, 39 (3), 525-547.

-Reyes Escobar, J. (2012). Importancia y repercusiones del pensamiento de Dilthey en la hermenéutica filosófica del siglo XX. Revista de Filosofía, (23), 97-113.

-San Agustín (1963). De civitate Dei. Obras (J. Morán, Ed.). Madrid: Biblioteca de Autores Cristianos.

-San Agustín (1964). Sermones. Obras (A. del Fueyo, Ed.). Madrid: Biblioteca de Autores Cristianos.

-San Agustín (1967). Epistolae. Obras (L. Cilleruelo, Ed.). BAC. Madrid: Biblioteca de Autores Cristianos. 
-San Agustín (1968). In Ioannis Evangelium tractatus. Obras (T. Prieto, Ed.). Madrid: Biblioteca de Autores Cristianos.

-San Agustín (1974). Las Confesiones. Obras (Á. Custodio Vega, Ed.). Madrid: Biblioteca de Autores Cristianos.

-San Agustín (1979). Introducción general y primeros escritos. Obras (V. Capánaga, Ed.). Madrid: Biblioteca de Autores Cristianos.

Sumario: Introducción; 1. Interpretación de las nociones de juicio moral, acción correcta y razón desde la perspectiva de la experiencia interior 2. Meditación y experiencia interior; 3. Disposición, experiencia y mundo; 4. Trascender es interrogar-se; Conclusión; Referencias. 